\title{
Círculos de leitura e letramento literário em espaços de privação de liberdade
}

Patrícia Gonçalves Jorge ${ }^{1}$, Karina Zendron da Cunha ${ }^{2}$, Suelen Ramos ${ }^{3}$

\section{Resumo}

A leitura é uma ferramenta valiosíssima na formação do sujeito e, por esse motivo, deveria ser tratada como um direito cultural ao qual todos os cidadãos deveriam ter acesso. Contudo, não é essa a nossa realidade. Neste artigo, pretendemos elucidar a importância da leitura, bem como o modo como ela vem sendo tratada nas escolas e no ambiente carcerário. Muitos dispositivos legais versam sobre o direito que o apenado tem à educação e, abarcada por este direito, está também a leitura. Além disso, pretendemos socializar neste trabalho as ações do Projeto Contexto, que tem auxiliado, desde 2017, reeducandos de um presídio de Blumenau no acesso à literatura de qualidade e, por meio dela, à remição de pena, bem como o desenvolvimento de seu letramento literário. Objetivamos ainda, por meio deste artigo, refletir sobre a importância das ações previstas para o terceiro ano do projeto: a implementação de círculos de leitura no espaço carcerário.

\section{Palavras-chave}

Letramento literário. Remição pela leitura. Literatura no cárcere. Círculos de leitura.

${ }^{1}$ Graduanda em Letras na Universidade Regional de Blumenau, Santa Catarina, Brasil. E-mail: pjorge@ furb.br.

2 Doutora em Linguística pela Universidade Federal de Santa Catarina, Brasil; professora da Universidade Regional de Blumenau, Santa Catarina, Brasil. E-mail: kzcunha@ furb.br.

3 Graduanda em Letras na Universidade Regional de Blumenau, Santa Catarina, Brasil. E-mail: sueramos@furb.br. 


\title{
Reading circles and literary literacy in prison
}

Patrícia Gonçalves Jorge ${ }^{4}$, Karina Zendron da Cunha ${ }^{5}$, Suelen Ramos ${ }^{6}$

\begin{abstract}
Reading is a valuable tool in the subject's formation, and for this reason, it should be treated as a cultural right to which all citizens should have access. However, this is not our reality. In this article, we intend to elucidate the importance of reading, as well as the way it is being treated in schools and in the prison environment. Many legal provisions operate dealing with the right of the prisoners to education, the right also covering the reading activities. In addition, the aim of this article is to socialize the actions of the Context Project that, since 2017, has assisted many incarcerated students of the Blumenau prison in access to quality literature and, through it, to the remission of their sentences as well as the development of their literary literacy. We also intend to reflect on the importance of the actions planned for the third year of the project: the implementation of reading circles in the correctional facility.
\end{abstract}

\section{Keywords}

Literary literacy. Remission by reading. Literature in prison. Reading circles.

\footnotetext{
${ }^{4}$ Undergraduate student in Letras, Regional University of Blumenau, State of Santa Catarina, Brazil. E-mail: pjorge@furb.br.

$5 \mathrm{PhD}$ in Linguistics, Federal University of Santa Catarina, State of Santa Catarina, Brazil; professor at the Regional University of Blumenau, State of Santa Catarina, Brazil. E-mail: kzcunha@ furb.br.

${ }^{6}$ Undergraduate student in Letras, Regional University of Blumenau, State of Santa Catarina, Brazil. E-mail: sueramos@furb.br.
} 


\section{Introdução}

A leitura tem grande papel na construção do ser humano e é importante em todas as fases da vida, auxiliando os indivíduos em suas provações diárias, além de ampliar sua forma de enxergar o mundo e a si mesmos (PETIT, 2013). A leitura é uma prática privilegiada para qualquer pessoa, mas ainda mais o é para reeducandos privados de sua liberdade, pessoas que vivem em um ambiente hostil e que se beneficiam da leitura como meio de criar um espaço íntimo onde podem refletir sobre suas vidas e lidar com suas provações diárias.

Infelizmente, são poucos os sujeitos presos nas instituições penais brasileiras que têm pleno acesso aos direitos garantidos pela legislação vigente: educação, lazer, trabalho, ressocialização. Mesmo nesse cenário, o projeto "Remição pela leitura" foi criado pela Portaria Conjunta $\mathrm{n}^{\circ}$ 276, de 20 de junho de 2012, e aparece como uma alternativa à escassez de programas educativos dentro dos presídios do Brasil.

Esta norma vem baseando, desde 2017, as ações do projeto de extensão universitária "Contexto: ampliando o alcance à liberdade por meio da leitura no Presídio Regional de Blumenau”. O projeto é uma parceria entre a Secretaria de Justiça e a Universidade Regional de Blumenau (FURB) que visa a atender a legislação referente à remição de pena por leitura, além de promover o letramento literário no ambiente carcerário, com vistas a formar leitores competentes, sensibilizar por meio da literatura, além de ampliar o senso crítico e o repertório cultural dos participantes do projeto. Em 2017 e 2018, o projeto facilitou o acesso à literatura e à remição de pena para os reeducandos do Presídio Regional de Blumenau (PRB).

O objetivo deste artigo é socializar os resultados alcançados pelo projeto até o momento, além de discutir sobre a importância de se incluir círculos de leitura e letramento literário em projetos como este, uma vez que a leitura, pensada a partir da perspectiva do letramento literário, cria cidadãos críticos, sensíveis e forma leitores para o resto da vida. De acordo com Cosson (2018, p. 176),

as discussões dos círculos de leitura ajudam a desenvolver o alto raciocínio, favorecem o domínio da escrita e promovem o letramento literário em um movimento que incorpora à formação do leitor o prazer de ler e a construção compartilhada da interpretação.

Para socializar nossos resultados e discutir a importância dos círculos de leitura e letramento literário em projetos de remição de pena por leitura, organizamos nosso texto em cinco 
seções: na primeira, apresentaremos um breve histórico da importância que tem sido dada à literatura no ambiente escolar; na segunda, discorreremos sobre as privações de direitos às quais estão sujeitos os cidadãos em ambiente carcerário; na terceira, levantaremos algumas problemáticas de como a leitura é tratada no cárcere, dando enfoque à legislação que rege a remição pela leitura no cárcere e algumas problemáticas que dela surgem; na quarta, o foco será a análise dos resultados de nossas ações junto aos reeducandos do PRB e, na última seção, discorremos sobre a proposta de Cosson (2018) para a criação de leitura e de como essa proposta pode ser aplicada no PRB.

\section{A literatura no espaço escolar: um breve histórico e algumas problemáticas}

A experiência da literatura forma cidadãos, abre-nos para o outro, livra-nos de preconceitos, expande nossas visões de mundo e, também, nos revela verdades sobre nós mesmos com as quais, talvez, nunca tivemos contato. É clara a influência positiva da literatura na humanização do indivíduo e, por essa razão, ela deveria ocupar um lugar de destaque em nossas escolas. Mas, considerando tanto as disposições legais que regem o ensino, quanto a realidade material das salas de aula, não é isso que enxergamos. A literatura no espaço escolar nunca foi uma disciplina autônoma (ZAPONNE, 2018). De modo geral, ela sempre foi usada como um meio de estudar aspectos gramaticais do texto, por exemplo, ou então como um meio de atingir às exigências feitas pelos cursos de nível superior nos quais o aluno pretendia ingressar. Tanto a formação do sujeito como leitor quanto o estímulo à apreciação da obra literária como uma obra artística raras vezes são levados em consideração no espaço escolar.

Entretanto, não é em vão que à literatura é dada tão pouca importância. Estamos inseridos em uma realidade capitalista e, não se vê, em nosso congresso nacional, grande esforço no sentido de tornar a educação libertadora aos nossos estudantes. $\mathrm{O}$ foco acaba sendo preparar cidadãos para o mercado de trabalho, o que também refletirá no enfoque escolhido pelas universidades e faculdades na formação de professores.

Nesse contexto, vale pensar que o lugar - pequeno - dado à literatura tem relação direta com o sistema neoliberal que relaciona posses materiais como o único qualificativo dos "homens de bem", descartando outros bens simbólicos de natureza cultural ou mesmo moral e ética, contra o qual o caráter humanizador e formador da literatura poderia ser um bom antídoto. (ZAPPONE, 2018, p. 430).

Atualmente, a literatura é tratada de modos diferentes no ensino fundamental e médio e em nenhum desses espaços ela é ensinada de maneira a formar o estudante como leitor ou como 
cidadão crítico. No fundamental, são priorizados textos curtos e a variedade de tipos textuais é grande. Trabalha-se receita, texto informativo, manuais, bulas. Os romances, por serem extensos, acabam sendo deixados de lado e, quando trabalhados, são através de excertos. Já no ensino médio, estudam-se as escolas literárias e seus autores mais proeminentes. Trabalhase também com resumos de obras para que os estudantes não tenham o trabalho de lê-las por completo para passar em exames vestibulares (COSSON, 2016).

É consenso em nossa sociedade que ler é um hábito importante, mas crianças que não têm contato com a literatura em casa, também, em sua grande maioria, não estão sendo bem servidas na escola. Para que esse cenário se modifique, elucida Cosson (2016, p. 23):

é fundamental que se coloque como centro das práticas literárias na escola a leitura efetiva dos textos [...]. Essa leitura também não pode ser feita de maneira assimétrica e em nome de um prazer absoluto de ler. Ao contrário, é fundamental que seja organizada segundo os objetivos da formação do aluno, compreendendo que a literatura tem um papel a cumprir no âmbito escolar.

As aulas de literatura deveriam ter como função apresentar os estudantes à literatura; é na escola que deveria se ensinar a interpretar e a manipular a linguagem. É a esse processo que chamamos letramento literário. E, como consequência da ausência desse tipo de formação, os estudantes saem da escola sem ter suas capacidades interpretativas bem desenvolvidas (COSSON, 2016).

Como vimos, a literatura não tem aparecido de forma adequada tanto na teoria quanto na prática das escolas. A seguir, discorreremos sobre a situação a qual estão submetidos os jovens encarcerados no Brasil e seu contato com a literatura.

\section{A realidade do cárcere brasileiro}

A Constituição de 1988 afirma que a educação é um direito de todos, não importando se o cidadão se encontra privado de sua liberdade ou não. O objetivo dessa seção é analisar qual o perfil e as condições às quais está submetida a população carcerária brasileira.

Os dados do Conselho Nacional do Ministério Público (CNMP) mostram que a situação nos ambientes de privação de liberdade é precária no Brasil. De acordo com o estudo, a taxa de lotação em 2015 foi de 160,34\% (BRASIL, 2016). Isso quer dizer que o Brasil está prendendo 
mais, como confirmam dados do Infopen $^{7}$ de 2016, os quais demonstram que houve um aumento de 707\% na população carcerária desde 1990 (BRASIL, 2017, p. 9). Além disso, $40 \%$ da população carcerária é formada por cidadãos que aguardam julgamento (BRASIL, 2017). O relatório também informa que 55\% dos detentos são jovens de 18 a 29 anos, sendo que, em comparação com a população total brasileira, a porcentagem de jovens é de $18 \%$ (BRASIL, 2017).

Analisando os dados das prisões brasileiras, não é difícil notar a evidente criminalização da pobreza da qual as instituições brasileiras são responsáveis. Não só jovem, a maioria da população carcerária também é pobre, visto que $61 \%$ dos presos não possuem o ensino fundamental completo, característica ligada à pobreza (BRASIL, 2017). O jovem marginalizado, por vários fatores, não obteve uma educação de qualidade fora da prisão. Sendo inserido no cárcere, as estatísticas do Infopen nos mostram que as oportunidades também não são amplas: apenas $12 \%$ dos presos participam de atividades de cunho educacional dentro ou fora das prisões (BRASIL, 2017, p. 53).

Apesar da realidade do cárcere, a Lei de Execução Penal (LEP), garante ao apenado o direito à educação em seus artigos 17 a $18^{\mathrm{a}}$, que afirmam que os reeducandos têm direito ao ensino fundamental obrigatoriamente e, também, ao ensino profissionalizante e de nível médio, obedecendo ao princípio constitucional da universalização da educação. Em seu art. 25, a LEP garante o direito ao trabalho; no art. 41, inciso V, direito à recreação e inciso VI, ao esporte. A lei também prevê, no art. 21, que todas as unidades prisionais devem possuir uma biblioteca.

Apesar da LEP garantir o direito ao trabalho, somente $15 \%$ dos brasileiros presos usufruem desse direito e a maioria é explorada pelas empresas em que trabalham, visto que $75 \%$ dos trabalhadores presos ou não recebem nenhum tipo de remuneração ou recebem menos de 3/4 do salário mínimo, o que infringe ao art. 29 da LEP (BRASIL, 2017, p. 58).

De acordo com o CNMP nenhum dos direitos citados garantidos pela LEP são plenamente contemplados nas instituições prisionais brasileiras. Além dos dados referentes à educação e ao trabalho no ambiente prisional, o relatório do CNMP acrescenta, ainda, que apenas 43,53\% das unidades têm biblioteca e, destas, 71,70\% garantem acesso aos encarcerados. Em relação ao acesso à cultura e ao lazer, 47,15\% das unidades fornecem esse tipo de atividades e, ainda,

\footnotetext{
${ }^{7}$ O Infopen é um sistema de informações estatísticas do sistema penitenciário brasileiro.
} 
o percentual de unidades que fornecem prática esportiva a seus detentos é de 57,93\%. (BRASIL, 2016, p. 64)

A realidade do cárcere não é ideal, e, no sentido de fornecer uma alternativa ao restante dos detentos que não têm acesso à educação, instituiu-se o projeto "Remição pela Leitura" pela Portaria Conjunta n. 276, de 20 de junho de 2012, que será discutida na seção que se segue juntamente com algumas implicações inerentes à sua implantação.

\section{A literatura no espaço carcerário}

De acordo com a LEP, o detento pode obter remição de sua pena por meio de práticas educacionais e laborais. Como o acesso ao trabalho e à educação ao encarcerado depende de ele ter sorte em estar em uma unidade que lhe forneça essas oportunidades, previu-se então, também na Portaria Conjunta n ${ }^{\circ} 276$, de 20 de junho de 2012, a remição de pena por meio da leitura no Sistema Penitenciário Federal.

A leitura é uma prática educacional que constrói sujeitos críticos, sensíveis ao outro e capazes de dialogar com a variedade de signos e sentidos pelos quais são rodeados no convívio em sociedade. No cárcere, o sujeito é submetido a um contexto em que vê sua autonomia diminuída, na medida em que precisa seguir as normas e protocolos estipulados pela instituição penitenciária. Para Petit (2013, p. 66-67), a leitura é uma ferramenta valiosa na reconquista do espaço íntimo do sujeito encarcerado, pois

a leitura pode ser um atalho privilegiado para elaborar ou manter um espaço próprio, íntimo, privado. Como prolongamento desse aspecto, a leitura pode ser um recurso para dar sentido à experiência de alguém, para dar voz a suas esperanças, a suas desventuras, a seus desejos; a leitura pode também ser um auxiliar decisivo para que se recupere e encontre a força necessária para sair de algo; e, finalmente, outro elemento fundamental, a leitura é uma abertura para o outro, pode ser o suporte para os intercâmbios.

De acordo com a Portaria citada, o preso participará do projeto de remição de maneira voluntária, sendo a ele entregue uma obra literária que terá de ser lida em um período de 21 a 30 dias. Posteriormente, o detento escreverá uma resenha que, se aprovada por uma comissão avaliadora formada por funcionários da instituição e, posteriormente, pelo Juiz de Execução Penal, renderá ao educando a remição de quatro dias em sua pena. 
A leitura se apresenta como forma alternativa de se ter acesso à educação em instituições que não podem garantir a todos o direito de estudar. Porém, para que a remição pela leitura tenha êxito, é preciso que se faça uso de obras adequadas à escolaridade do apenado e, ainda, é preciso que pessoas qualificadas escolham a obra que será entregue ao detento, o que passa a ser um novo desafio, visto que, de acordo com Julião e Paiva (2014, p. 117), "do acervo existente [nas bibliotecas prisionais], a maior parte é fruto de doações”. As bibliotecas das unidades carcerárias possuem em seu acervo obras que não se assemelham ao nível de compreensão da maioria dos apenados. Que reeducando sem ensino fundamental completo (maioria da população carcerária) se interessaria em ler, ou melhor, teria condições de ler, um cânone da literatura com vocabulário rebuscado?

Sobre os problemas que os projetos de remição pela leitura enfrentam, Faria e Oliveira (2014, p. 13) destacam:

Partindo do pressuposto de que a leitura é uma atividade de estudo, dotada de caráter educacional, percebe-se que também esta deve seguir as etapas pedagógicas nas quais todos os cursos e modelos de aprendizado se baseiam. Mais do que uma leitura de Dostoievski ou qualquer outro autor consagrado, esta forma de remição, aceitando seus próprios pressupostos educacionais, deve ser estruturada de forma a respeitar os níveis de conhecimento de cada indivíduo que se beneficiará dela, e de contribuir para que capacidades adicionais sejam obtidas após o cumprimento correto da tarefa de leitura.

Em tese, assim como prevê a referida Portaria, o reeducando passaria por Oficinas de Leitura que teriam como função orientá-lo sobre os critérios aos quais deve obedecer sua resenha. Contudo, como colocam Faria e Oliveira (2014), sabemos que o processo educativo é lento. Leva tempo até que o reeducando adquira as competências previstas pela norma, o que pode acarretar na desmotivação do indivíduo ao ver seu trabalho rejeitado. Explicam os autores:

Ao ter seu relatório rejeitado por sua incapacidade de compreensão e síntese nos moldes estáticos estabelecidos pela comissão e pelo magistrado da execução, o que acontece com o detento é exatamente o descrito acima: desestimula-se a leitura daquele que se encontra em estágio inicial de sua formação educacional e, consequentemente, aborta-se a iniciativa do preso em busca [sic] melhorias em sua própria educação. Tal desestímulo só contribui para o fortalecimento da marginalização daquele que não teve oportunidade de se formar na educação básica. (FARIA; OLIVEIRA, 2014, p. 20).

Qualquer atividade educacional relacionada à leitura deve ter como objetivo o aprimoramento do letramento literário, que, de acordo com Lajolo (2016), leva o leitor a compreender a simbologia de uma obra bem como as verdades e questões sobre a condição humana que a 
literatura carrega. Nesse sentido, é importante também a adequada seleção da obra em relação à sua relevância social e à sua relevância ao leitor. A leitura é um processo dialógico entre leitor e obra, que tem potencial de gerar criticidade, acolhimento, descobertas e reflexões no leitor.

\section{Ações do Projeto Contexto: a remição de pena pela leitura no Presídio Regional de Blumenau}

O Projeto Contexto, uma parceria entre o PRB e a FURB, teve suas ações iniciadas em 2017 como um projeto de extensão universitária. Participam dele docentes e discentes dos cursos de Letras, Direito e, desde o início de 2019, Pedagogia.

O projeto segue às diretrizes da LEP, que versa sobre a remição pelo trabalho e pelo estudo dos apenados, a Portaria Conjunta $n^{\circ}$ 276/2012, que institui, no âmbito das penitenciárias federais, o projeto de "Remição pela Leitura" e, ainda, a Portaria $n^{\circ}$ 006/2016, que versa exclusivamente sobre o projeto realizado pela parceria entre a FURB e o Presídio Regional de Blumenau. De acordo com esta última Portaria, o reeducando tem de 21 a 30 dias para ler a obra e, após esse período, é feita a aplicação de uma prova dividida em duas partes: a primeira refere-se à elaboração de uma resenha crítica e a segunda, a uma prova oral com um dos integrantes da equipe do Projeto Contexto.

$\mathrm{Na}$ seção anterior, foram abordadas algumas dificuldades enfrentadas, eventualmente, pelos reeducandos de baixa escolaridade para participarem de projetos desse tipo. E, justamente para acolher àqueles que não tiveram boa base educacional é que a Portaria $n^{\circ}$ 006/2016 previu que se instituísse, juntamente com a resenha prevista pela Portaria Conjunta $\mathrm{n}^{\circ}$ 276/2012, uma avaliação oral, em que o reeducando tem a chance de se expressar verbalmente com o avaliador, para que sua nota não seja prejudicada caso tenha dificuldade com a modalidade escrita. Ao longo do percurso do Projeto Contexto, foram enviados ao Juiz de Execução Penal 322 pareceres atestando que os reeducandos em questão obtiveram nota satisfatória em sua avaliação.

No começo do projeto, entre os períodos de 23/03/17 e 28/08/17, a média de aprovação nas avaliações foi de apenas 20,6\%, isso porque, em primeiro lugar, muitos reeducandos não apareciam para fazer a prova e também, porque, no início, as obras às quais tínhamos acesso 
para a utilização do projeto não eram compatíveis com a escolaridade ou as preferências do reeducando. Porém, a partir da rodada avaliativa de 09/10/17, pudemos observar uma considerável melhora no desempenho dos reeducandos participantes: 73,2\% deles tiveram êxito em sua avaliação. Nossos índices, desde então, têm se mantido estáveis, na faixa dos 75$85 \%$ de êxito nas avaliações.

Em de agosto de 2017, por meio de licitação, foram adquiridas novas obras escolhidas pela equipe do projeto para serem utilizadas no projeto. Somando-se ao fato de que as evasões foram diminuindo e os participantes foram se adaptando aos poucos ao projeto, entendemos que essas são as razões da melhora no desempenho dos reeducandos vinculados ao projeto.

Pudemos perceber pelas falas dos reeducandos e por seus resultados, que, além de tirarem bom proveito das leituras, demonstraram progresso em sua escrita, capacidade de síntese e elaboração de opiniões nesse percurso de dois anos. É notável o modo como a literatura tem sido um fator positivo em suas vidas. Reeducandos e funcionários do PRB têm comentado ser comum encontrar duas ou mais pessoas conversando sobre suas leituras no presídio.

Quando questionados sobre seu interesse por círculos de leitura e oficinas de escrita, ficou claro o grande interesse dos reeducandos por esta, visto que demonstram preocupação com a qualidade da sua escrita. E, de fato, tal consideração se faz muito pertinente, visto que, de acordo com a Portaria Conjunta 276, de 20 de junho de 2012, as atividades de remição pela leitura não se resumem à leitura de livros, mas prevê que se faça uma preparação no sentido de instruir os reeducandos no que concerne à redação de suas resenhas e o que tipos de apontamentos são deles esperados.

Sabemos dos benefícios da roda de leitura na experiência do leitor. Ali, o reeducando terá acesso a opiniões diferentes, ao contraditório, essencial para que se forme como leitor e construa uma noção de respeito a opiniões contrárias. Sobre os aspectos positivos dos círculos de leitura, Cosson (2018) explica que eles "possuem um caráter formativo, proporcionando uma aprendizagem coletiva e colaborativa ao ampliar o horizonte interpretativo da leitura individual por meio do compartilhamento das leituras e do diálogo em torno da obra selecionada" (COSSON, 2018, p. 139). Algumas ideias propostas para a execução dos círculos de leitura no PRB em 2019 serão mostradas na próxima seção. 
Dentre os títulos mais citados como favoritos pelos reeducandos estão as obras: "Os Goonies", de James Kahn, a trilogia "Jogos Vorazes", de Suzanne Collins, "Capitães da Areia", de Jorge Amado, "Harry Potter e a Pedra Filosofal", de J.K. Rowling, "Jim Knopf e Lucas, o Maquinista", de Michael Ende, “A Culpa é das Estrelas”, de John Green, "Pílulas Azuis", de Frederik Peeters, "Nimona”, de Noelle Stevenson, "O Velho e o Mar", de Ernest Hemingway, “1984”, de George Orwell, "Viagem ao Centro da Terra”, de Júlio Verne, "Cidade de Deus", de Paulo Lins, "O Nome da Rosa", de Umberto Eco, "Vinte Mil Léguas Submarinas”, de Júlio Verne e "O Cavaleiro Inexistente”, de Italo Calvino.

Na escolha dos títulos, o projeto procurou contemplar todos os tipos de leitores, desse modo, encontramos na lista dos livros usados no projeto best-sellers, livros infanto-juvenis e clássicos da literatura. Para que se formem leitores, é preciso que se faça um trabalho gradual na seleção das obras, para que o leitor seja desafiado a dar um passo a cada vez que pegar um livro novo na mão. É importante que o leitor não fique estagnado em apenas um tipo de leitura, mas que seja desafiado a ir mais além e tornar-se um sujeito plenamente letrado.

Entre algumas das queixas ouvidas dos reeducandos estão a dificuldades em ler livros muito longos e livros de contos e crônicas, por não lembrarem das histórias destes na hora de escrever a resenha. Alguns também relatam ter dificuldade em decorar os nomes dos personagens.

Quando o livro avaliado é de contos ou crônicas, procuramos pedir ao reeducando que nos conte apenas algumas das histórias dos livros, os quais lhes chamaram mais atenção ou, ainda, na avaliação oral, às vezes fazemos algumas perguntas específicas sobre determinados textos para verificar se o reeducando consegue se lembrar de mais informações sobre a obra, afinal a ideia não é que o participante escreva um resumo do livro com muitos detalhes, mas sim, que nos dê uma ideia geral da obra e de sua avaliação como leitor, de que pensamentos a leitura o despertou.

Ainda, muitas sugestões foram ouvidas dos reeducandos atendidos como a possibilidade de ler mais livros durante o ano, a inserção de um maior número de reeducandos no projeto e também a possibilidade de escolherem o título que lerão. 
Por mais que se concorde com tais demandas, possuímos uma equipe de docentes, discentes e voluntários que é ainda pequena para atender a mais reeducandos. Também não é viável que cada reeducando escolha a sua obra por não termos uma equipe que possa ler muitos livros de um mês para outro para posterior avaliação, além de não contarmos com muitos títulos na biblioteca do PRB.

Enxergamos, dentro do Presídio, um grande engajamento e aceitação em relação ao Projeto Contexto. Tanto funcionários como reeducandos mostram-se muito otimistas e trazem boas sugestões para ampliação do projeto. Sabemos que projetos que são capazes de humanizar o encarcerado e dar-lhe alguma sensação de pertencimento e acolhimento são raros nas instituições prisionais brasileiras. Por isso, julgamos como algo positivo o forte apoio da comunidade do PRB em relação às nossas ações.

\section{As vantagens dos círculos de leitura em ambientes de privação de liberdade}

Não nos construímos leitores sozinhos, a sociedade e a escola têm grande papel nisso. Enquanto a escola é a principal responsável por nos ensinar a interpretar um texto, a sociedade em que vivemos tem grande influência em como leremos uma obra, ou o que leremos: "Ler implica troca de sentidos não só entre escritor e leitor, mas também com a sociedade onde ambos estão localizados, pois os sentidos são resultados de compartilhamentos de visões de mundo entre os homens no tempo e no espaço" (COSSON, 2016, p. 27).

Desse modo, entendemos que nenhuma leitura que fazemos de um livro é livre de influências. Dialogamos com a obra, com a sociedade e com a comunidade de leitores em que estamos inseridos e, por meio dessas influências, construímo-nos como leitores. Sabendo disso, nossa proposta é que, no ano de 2019, o Projeto Contexto estabeleça, dentro do PRB, círculos de leitura, nos quais os reeducandos terão a chance de compartilhar impressões sobre suas leituras, ouvir as ideias dos companheiros, discordar ou concordar e, juntos, tentarem apreender sentidos mais profundos que se encontram na obra lida. A prática do círculo de leitura é uma estratégia valiosa para o letramento literário dos reeducandos, e acreditamos ser o próximo passo para aprimorarmos a efetividade de nossas ações dentro do PRB.

Para Cosson (2018), por meio dos círculos de leitura, a aprendizagem se dá de maneira coletiva, "ampliando o horizonte interpretativo da leitura individual" e também estreitando os 
laços entre os leitores e fortalecendo a empatia com o próximo. Para o autor, a prática do círculo de leitura é privilegiada, pois: "ao lerem juntos, os participantes do grupo tornam explícito o caráter social da interpretação dos textos e podem se apropriar do repertório e manipular seus elementos com um grau maior de consciência." (COSSON, 2018, p. 139)

Ainda, de acordo com Petit (2013):

A leitura pode sacudir crenças bem estabelecidas até então, desvirtuar uma representação do mundo baseada na oposição entre "eles" e "nós". Porém, se às vezes pode relaxar certos vínculos comunitários, também convida a outras formas de vínculo social, a outras formas de pertencer a uma sociedade. (PETIT, 2013, p. 113).

Ou seja, a leitura em si já é uma ótima prática para que se enxergue o outro de maneira diferente e mais livre de preconceitos e, associada à prática do círculo de leitura, é capaz de gerar aprendizados e criar uma relação saudável com o outro e com aqueles de quem discordamos.

Com objetivo de ampliar as ações do Projeto Contexto, visando ao letramento literário dos reeducandos participantes, foram elaborados três modelos de círculos de leitura, destinados, respectivamente, a leitores iniciantes, intermediários e que já obtiveram progresso significativo em sua jornada de leituras. Sobre a importância de guiar o leitor iniciante e, aos poucos, deixá-lo desenvolver sua autonomia, explica Cosson (2018, p. 159-160):

Esse percurso temporal compreende um processo formativo que é a aprendizagem da leitura compartilhada. Os alunos que estão iniciando a formação de leitor ou nunca participaram desse tipo de atividade precisam ser mais fortemente guiados na leitura e discussões do que aqueles mais maduros como leitores.

$\mathrm{Na}$ entidade penitenciária parceira, há uma grande rotatividade nos reeducandos que participam do projeto já em andamento, isso porque muitos deles têm suas situações penais alteradas durante nossas ações. O Modelo I pensado para o círculo de leitura tem o objetivo de atender a esse público e tem enfoque em leitores iniciantes. Aqui, usaremos textos curtos, como crônicas, contos, poemas, com um grupo de nove reeducandos e um integrante do Projeto Contexto para fazer a condução, tendo duração estimada de uma hora.

No primeiro encontro, todos se sentarão em círculo e o condutor explicará aos participantes como funciona a prática do círculo de leitura e, em conjunto, pedirá que os reeducandos estabeleçam regras de conduta e responsabilidade, temática dos textos e qual será o 
cronograma dos encontros. As normas, então, serão transcritas em um cartaz que será preso à parede do espaço destinado aos encontros. A dinâmica possibilitará ao condutor amadurecer as próximas propostas de atividades para essa comunidade de leitores.

Enquanto é feita a leitura do texto em voz alta pelo mediador do círculo, os reeducandos serão instruídos a trabalhar em grupo ou individualmente, destacando partes do texto que lhes chamaram atenção, personagens, espaço ou vocabulário desconhecido para posterior uso na discussão. Caso os participantes apresentem dificuldade em selecionar elementos-chave do texto, o condutor mostrará a eles como fazê-lo por meio da modelagem, prática em que o condutor dá exemplos de como enxergar elementos significativos na narrativa, como explica Cosson (2018, p. 166): “Alunos em processo de formação precisam ser modelados sobre como elaborar e responder a questões abertas, como aprofundar a leitura para além do resumo da história, como se manter dentro do assunto e outros aspectos".

Depois de finalizada a leitura, os participantes serão convidados a socializar suas impressões sobre o texto e suas anotações. Caso o condutor note em um dado momento que a discussão não está se desenvolvendo, ele introduzirá uma pergunta geradora para dar continuidade à discussão. É importante que, após a finalização da discussão, os participantes avaliem o círculo por escrito, por meio de um breve texto e/ou respondendo a questões com Escala Likert, para que as anotações sirvam de base para a escolha dos textos a serem trabalhados nos próximos encontros.

Em um primeiro encontro, o condutor trará textos que considera relevantes à comunidade de leitores, justificando suas escolhas, mas, depois de ter as primeiras impressões, o condutor passará a fazer uma melhor seleção dos textos tendo em vista as discussões e avaliações fornecidas pelos participantes. Nesse sentido, Cosson (2018) explica a importância da seleção de textos relevantes à comunidade de leitores e seus interesses:

não há um texto ideal para os círculos de leitura, mas sim textos adequados àquela comunidade de leitores. Essa adequação depende das características dos participantes, do ambiente em que se desenvolve o círculo e os objetivos e interesses de sua composição, mas de um modo geral vale a máxima de que texto adequado é aquele que é bom para ler e para discutir. (COSSON, 2018, p. 160)

O Modelo II foi pensando como um modelo mais avançado de círculo, em que os participantes terão contato com narrativas mais longas e a responsabilidade de conduzir os círculos. Este círculo, que terá a duração estimada de 1 h15min, contará com a participarão de 
oito reeducandos e um membro da equipe do Projeto Contexto para orientar e fazer a préseleção das obras. O orientador trará várias opções de textos para que os participantes escolham antes de cada círculo. Na medida em que enxerga o progresso dos participantes, por meio da compreensão dos sentidos do texto e da maior complexidade de suas reflexões, o condutor introduzirá textos de maior complexidade estilística.

Depois de explicadas como serão as práticas do círculo, o cronograma e a escolha da obra, como no Modelo I, o orientador pedirá a um voluntário que, com ele, conduza os trabalhos do círculo, seguindo a prática de modelagem proposta por Cosson (2018). Nos próximos encontros, a dupla condutora será formada por dois reeducandos, revezando-se no processo, até todos terem a chance de conduzir a prática. Com as carteiras organizadas na forma de um círculo, a dupla condutora se revezará para ler o texto em voz alta e os demais participantes serão instruídos a usarem post-its para anotar suas impressões sobre o texto ou o que lhes chamou atenção. Ao final da leitura, terão, ainda, mais um momento para que finalizem suas anotações, que serão posteriormente coladas em um cartaz destinado a ficar preso na parede da sala dos encontros. Deste modo, a cada sessão, os reeducandos terão disponíveis a evolução das reflexões anteriores e posteriores às discussões. Depois disso, retornam todos às suas carteiras para o início às discussões. A discussão deverá ocorrer naturalmente com interferências do orientador, caso seja necessário, para levá-la adiante.

Depois de finalizada a discussão da obra, os participantes serão convidados novamente a escreverem em post-its suas impressões e reflexões sobre o que foi discutido e colá-los junto aos que redigiram mais cedo, a fim de tê-los lado a lado para o último momento do círculo, em que eles refletirão sobre a evolução de suas interpretações. Depois disso, como no Modelo I, os participantes farão a avaliação do círculo de leitura.

Já o Modelo III visa a atender reeducandos com maior nível de letramento literário. Aqui, participarão seis reeducandos e um orientador, e serão usados textos longos a serem lidos pelos participantes previamente à prática do círculo de leitura. Em um primeiro encontro, os participantes serão orientados a escrever um diário de leitura em que anotarão, à medida que leem, partes importantes da narrativa e o que lhes chamou a atenção.

Sobre a importância do registro, Cosson (2018, p. 171) explica: "a fase do registro é o momento em que os participantes refletem sobre o modo como estão lendo e o funcionamento 
do grupo, assim como sobre a obra e a leitura compartilhada. Esse registro deve acontecer ao final da leitura total da obra".

Também, nesse primeiro encontro, os participantes farão a escolha do livro. O condutor justificará a escolha das obras que a eles dispuser, falando um pouco de cada uma e pedirá que os reeducandos votem naquela que lhes despertou maior interesse. Neste momento também será definido o cronograma dos encontros.

Depois do primeiro encontro de orientação, haverá o primeiro círculo deste modelo. A primeira atividade terá duração de 30 minutos, sendo cinco destinados a cada reeducando para que socialize suas impressões individuais sobre a obra. Depois disso, se iniciará a discussão coletiva da obra. Os 30 minutos finais serão dedicados à complementação do diário de leitura com qualquer assunto discutido que lhes chamou a atenção, se mudaram de ideia, o que acharam da opinião dos outros participantes do grupo, entre outros. O orientador, então, pedirá aos reeducandos que avaliem os trabalhos do encontro de maneira breve e oral. Depois disso, os diários de leitura serão entregues ao orientador, para que ele monitore os avanços dos participantes. Ficará agendada uma data para que haja a devolutiva dos diários bem como a escolha de uma nova obra.

De maneira progressiva e coletiva, esperamos que os reeducandos apreendam sentidos cada vez mais complexos de suas leituras, que se formem como leitores, que aprimorem seu uso da linguagem e que se beneficiem dos laços sociais que os círculos de leitura são capazes de criar.

É importante que todo processo de formação do leitor seja permeado pelo respeito, que todas as contribuições sejam validadas e, ainda, que os reeducandos se sintam livres para expor suas ideias, sem que se sintam avaliados:

essas discussões são espaços de compartilhamento e não ensinamento, ou seja, um membro do círculo não vai ensinar o outro, mas sim compartilhar sua leitura que não precisa ser negada nem aceita, mas exposta a todos. Daí que nessas discussões não haja respostas certas ou erradas, mas sim perguntas autênticas que querem realmente entender e compreender o que se leu em comum. As perguntas que se fazem dentro de um círculo de leitura jamais devem ser colocadas para checar se o participante realmente leu o texto, seus conhecimentos sobre o autor, a literatura e tudo o mais que é matéria de ensino escolar. (COSSON, 2018, p. 170).

Como aponta Cosson (2018), os círculos de leitura são espaços onde reflexões e visões de mundo vêm à tona e são compartilhadas. Ali, os reeducandos constroem e desconstroem, 
juntos, suas interpretações em uma prática que permite, além de tudo, que se estabeleçam laços sociais.

\section{Considerações finais}

A literatura tem relevante função na inserção do indivíduo na sociedade, pois o leitor proficiente é capaz de apreender sentidos que só quem passou por um bom processo educacional teve acesso. Pela importância que a leitura tem na libertação do indivíduo, ela deveria ser tratada como um direito de todo cidadão.

Sabemos que os estudantes, em liberdade ou não, estão sendo privados do direito a uma educação de qualidade. A literatura, mesmo na educação básica, não é ensinada com o objetivo de formar leitores ou cidadãos críticos. Se é esse o cenário nas escolas, a situação só se faz piorar no ambiente carcerário. Apesar de a Portaria Conjunta $n^{\circ} 276$ prever o direito à remição de pena por meio da leitura no sistema penitenciário, poucas são as unidades prisionais que oferecem esse direito aos apenados e aquelas que oferecem enfrentam inúmeros problemas.

Diante desse cenário, a prática no Projeto Contexto, mesmo enfrentando inúmeras dificuldades, tem nos mostrado o impacto que a leitura é capaz de trazer aos sujeitos no cárcere. Enxergamos o avanço nas composições orais e escritas de nossos reeducandos. Além disso, o interesse deles em participar do projeto, algo demonstrado pela forte demanda que obtivemos na expansão do projeto, fazem-nos crer que estamos no caminho certo.

Nosso intuito é que, nos próximos anos, a implantação de círculos de leitura fortaleça nosso trabalho de letramento literário, fornecendo aos reeducandos um espaço em que possam compartilhar interpretações e reflexões, sempre conectadas à sua vida íntima, com a qual a leitura invariavelmente se relaciona.

\section{Referências}

AZEVEDO, R. Formação de leitores e razão para a literatura. In: SOUZA, R. J. de (org.). Caminhos para a formação do leitor. São Paulo: DCL, 2004. p. 38-47.

BLUMENAU. Poder Judiciário de Santa Catarina - Comarca de Blumenau. $3^{\text {a }}$ Vara Criminal. Portaria $\mathrm{n}^{\circ}$ 006, de 20 de setembro de 2016. Disponível em: http://www.oabbnu.org.br/attachments/article/14038/Scan_20161003_183529.pdf. Acesso em: 7 mar. 2019. 
BRASIL. Conselho Nacional do Ministério Público. A visão do Ministério Público sobre o sistema prisional brasileiro. Brasília: CNMP, 2016. 344 p. Disponível em:

http://www.cnmp.mp.br/portal/publicacoes/9948-a-visao-do-ministerio-publico-sobre-osistema-prisional-brasileiro-2016. Acesso em: 24 fev. 2019.

BRASIL. Justiça Federal. Conselho de Justiça Federal. Portaria Conjunta $n^{\circ}$ 276, de 20 de junho de 2012. Disciplina o Projeto da Remição pela Leitura no Sistema Penitenciário Federal. Disponível em:

http://www.cjf.jus.br/cjf/documentos/portaria_remissaopelaleitura.pdf/view. Acesso em: 7 mar. 2019.

BRASIL. Lei n ${ }^{\circ}$ 7.210/84, de 11 de julho de 1984. Institui a lei de execução penal. Disponível em: http://www.planalto.gov.br/ccivil_03/Leis/L7210.htm. Acesso em: 7 mar. 2019.

BRASIL. Ministério da Justiça e Segurança Pública. Departamento Penitenciário Nacional. Levantamento Nacional de Informações Penitenciárias: INFOPEN. Brasília: DPN, 2017. Disponível em: http://depen.gov.br/DEPEN/noticias-1/noticias/infopen-levantamentonacional-de-informacoes-penitenciarias-2016/relatorio_2016_22111.pdf. Acesso em: 24 fev. 2019.

COSSON, R. Círculos de leitura e letramento literário. São Paulo: Contexto, 2018.

COSSON, R. Letramento Literário: teoria e prática. 2. ed. São Paulo: Contexto, 2016.

FARIA, A. A. M.; OLIVEIRA, A. G. R. De turma da Mônica a Crime e Castigo: a remição por leitura como uma oportunidade de autodidática. 2014. Disponível em:

http://www.publicadireito.com.br/artigos/?cod=2425ad56cc45acbd. Acesso em: 24 fev. 2019.

LAJOLO, M. Carlos Drummond de Andrade: uma história exemplar de leitura. In: SOUZA, R. J. de (org.). Caminhos para a formação do leitor. São Paulo: DCL, 2004. p. 12-23.

PETIT, M. Leituras: do espaço íntimo ao espaço público. São Paulo: 34, 2013.

ZAPPONE, M. H. Y. Literatura na escola brasileira: história, normativas e experiência no espaço escolar. Estudos de Literatura Brasileira Contemporânea, Brasília, n. 54, p. 409433, maio/ago. 2018. Doi: 10.1590/10.1590/2316-40185421.

Submetido em $1^{\circ}$ de abril de 2019.

Aprovado em 6 de maio de 2019. 